\title{
Steady-state solutions for subsurface chlorophyll maximum in stratified water columns with a bell-shaped vertical profile of chlorophyll
}

\author{
X. Gong, J. Shi, H. W. Gao, and X. H. Yao \\ Key Laboratory of Marine Environment and Ecology (Ministry of Education of China), Ocean University of China, \\ Qingdao 266100, China
}

Correspondence to: H. W. Gao (hwgao@ouc.edu.cn)

Received: 19 April 2014 - Published in Biogeosciences Discuss.: 18 June 2014

Revised: 14 January 2015 - Accepted: 14 January 2015 - Published: 16 February 2015

\begin{abstract}
A bell-shaped vertical profile of chlorophyll $a$ (Chl a) concentration, conventionally referred to as a subsurface chlorophyll maximum (SCM) phenomenon, has frequently been observed in stratified oceans and lakes. This profile is assumed to be a general Gaussian distribution in this study. By substituting the general Gaussian function into ecosystem dynamical equations, the steady-state solutions for SCM characteristics (i.e., SCM layer depth, thickness, and intensity) in various scenarios are derived. These solutions indicate that (1) the maximum concentration of $\mathrm{Chl} a$ occurs at or below the depth of maximum growth rates of phytoplankton located at the transition from nutrient limitation to light limitation, and the depth of SCM layer deepens logarithmically with an increase in surface light intensity; (2) thickness and intensity of the SCM layer are mainly affected by nutrient supply, but independent of surface light intensity; and (3) intensity of the SCM layer is proportional to the diffusive flux of nutrients from below, which becomes stronger as a result of this layer being shrunk by a higher light attenuation coefficient or a larger sinking velocity of phytoplankton. In addition, the limitation and potential application of the analytical solutions are also presented.
\end{abstract}

\section{Introduction}

Vertical profiles of chlorophyll $a(\mathrm{Chl} a)$ concentration in lakes, coastal seas, and open oceans are highly variable. However, a bell-shaped vertical profile of Chl $a$, conventionally referred to as a subsurface chlorophyll maximum (SCM) phenomenon, has been frequently observed in stratified water columns; for example, it occurs through the whole year in tropical and subtropical oceans, while it exists only during summer in temperate and high-latitude oceanic zones. The subsurface biomass maxima (SBMs) are also common in stratified water columns. The chlorophyll-to-biomass ratio generally increases with depth in the euphotic zone. Thus, SCMs may not necessarily represent SBMs (Cullen, 1982; Fennel and Boss, 2003) and are usually deeper than SBMs (Fennel and Boss, 2003; Hodges and Rudnick, 2004). However, the subsurface maxima in both chlorophyll and biomass are usually formed in certain regions of the water column where two opposing resource (light and nutrient) gradients combined with turbulent mixing are amenable for survival of phytoplankton. Thus, SCMs are approximately equal to SBMs in many studies (Klausmeier and Litchman, 2001; Sharples et al., 2001; Huisman et al., 2006; Raybov et al., 2010). Fennel and Boss (2003) reported that the photoacclimation of phytoplankton can be another important reason for forming an SCM in oligotrophic waters.

The SCM phenomenon can be characterized by the thickness, depth, and intensity of the SCM layer (SCML) (Beckmann and Hense, 2007). On-site observations (Platt et al., 1988; Sharples et al., 2001; Dekshenieks et al., 2001; Mellard et al., 2011) have shown the occurrence of SCML to be at a relatively shallow depth $(1-50 \mathrm{~m})$ and thin (several centimeters to a few meters) in lakes and coastal seas but with high concentration of Chl $a\left(1-100 \mathrm{mg} \mathrm{m}^{-3}\right)$. In open oceans, the SCML was deeper $(80-130 \mathrm{~m})$ and thicker (tens of meters), while the concentration of Chl $a$ was relatively low $\left(<1 \mathrm{mg} \mathrm{m}^{-3}\right.$ ) (Anderson, 1969; Platt et al., 1988). 
SCMs have attracted much attention because of the significant contribution of SCML to the total biomass and primary production in the whole water column (Cullen and Eppley, 1981; Weston et al., 2005; Siswanto et al., 2005; Hanson et al., 2007; Sullivan et al., 2010). Pérez et al. (2006) showed that $65-75 \%$ of the total Chl $a$ in a water column of the Atlantic subtropical gyres was presented in SCML, and the layer thickness was approximately $50 \mathrm{~m}$. Weston et al. (2005) reported that the SCML accounted for $58 \%$ of the water column primary production in the central North Sea, although the layer thickness was less than $5 \mathrm{~m}$. Sullivan et al. (2010) found that the fraction of Chl $a$ in the SCML (thickness $<3 \mathrm{~m}$ ) out of the total water column ranged from 33 to $47 \%$ in Monterey Bay, USA.

Many numerical studies have been conducted to link the thickness, depth, and intensity of the SCML to various environmental parameters (Jamart et al., 1979; Varela et al., 1994; Klausmeier and Litchman, 2001; Hodges and Rudnick, 2004; Huisman et al., 2006; Beckmann and Hense, 2007). The thickness of the SCML mainly depends on the degree of vertical mixing in lakes (Klausmeier and Litchman, 2001). In oligotrophic oceans, the light attenuation coefficient is the key factor in determining the SCML depth (Varela et al., 1994; Hodges and Rudnick, 2004; Beckmann and Hense, 2007) and the intensity of the SCML depends strongly on sinking velocity of phytoplankton and/or detritus and vertical diffusivity rather than growth rate of phytoplankton (Hodges and Rudnick, 2004; Beckmann and Hense, 2007). However, the thickness, depth, and intensity of SCML are very sensitive to variations of environmental parameters. Therefore, the relationships obtained from a particular case may not be applicable for other cases. To understand the general relationships between SCM phenomenon and environmental parameters, the analytical solution for dynamic ecosystem equations is needed.

The algae game theoretical model, pioneered by Klausmeier and Litchmann (2001), was perhaps the first model to derive the depth and intensity of SCML, although the SCML is assumed to be infinitely thin. The authors of the model adopted a delta function to approximate the phytoplankton distribution in this thin layer. Yoshiyama et al. (2009) used this model to examine more than one species competing for limiting nutrients and light below the surface mixed layer. Mellard et al. (2011) included stratification into this model. However, the SCML was still confined to an infinitely thin layer. In fact, many observations have shown that the thickness of SCML can reach as high as $100 \mathrm{~m}$ in oceans (Platt et al., 1988). For those cases, the assumption of an infinitely small thickness of SCML is contradictory to the observations.

In this study, we assume that the vertical profile of Chl $a$ can be approximately treated as a general Gaussian function instead of a delta function. This parameterizing approach was proposed firstly by Lewis et al. (1983), and has been widely used to fit vertical profiles of Chl $a$ (Platt et al., 1988; Weston

\section{Growth limitation by light and nutrients}

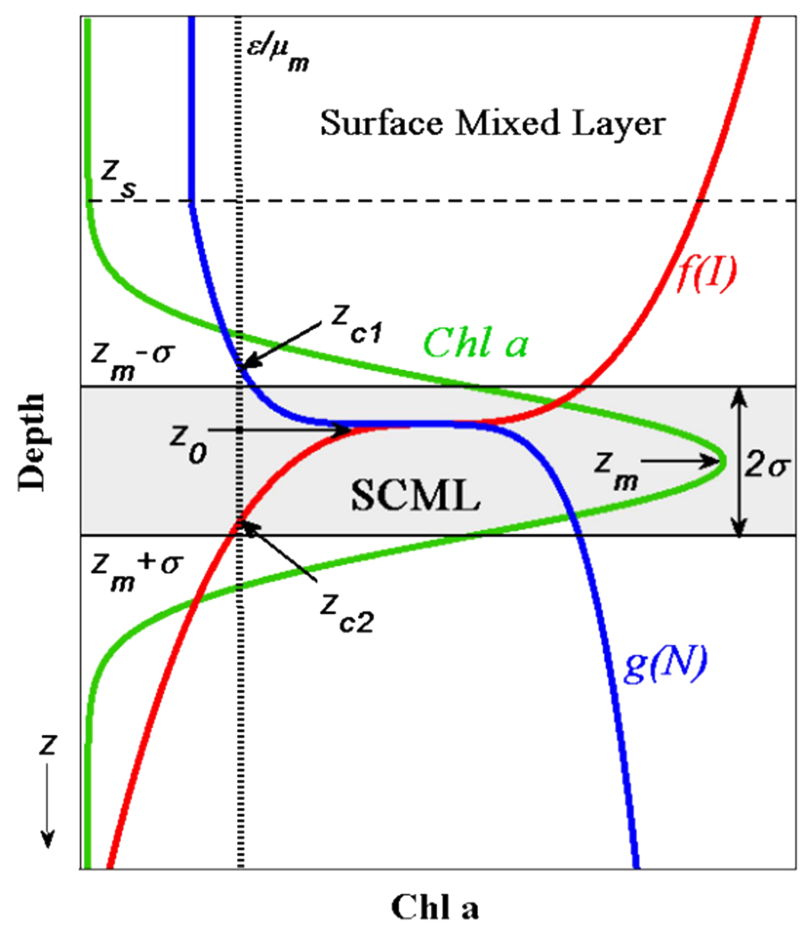

Figure 1. Schematic picture of $\mathrm{Chl} a$ distribution under the limitation by light and nutrient in stratified water columns (green solid line is Chl $a$ concentration as a function of depth; red solid line is the growth-limiting term with respect to light, $f(I)$; blue solid line is the growth-limiting term with respect to nutrients, $g(N)$; horizontal dashed line represents the depth of surface mixed layer, $z_{\mathrm{s}}$; horizontal solid lines indicate the locations of the upper and lower SCML, $z_{\mathrm{m}}-\sigma$ and $z_{\mathrm{m}}+\sigma$, respectively; vertical dotted line is the ratio of loss rate to maximum growth rate, $\varepsilon / \mu_{\mathrm{m}} ; z_{c 1}$ and $z_{\mathrm{c} 2}$ refer to the two compensation depths where $\mu_{\mathrm{m}} g(N)=\varepsilon$ and $\mu_{\mathrm{m}} f(I)=\varepsilon$, respectively; $z_{0}$ and $z_{\mathrm{m}}$ indicate the depths of maximum in growth rates and in Chl $a$ concentrations, respectively; and double arrow represents the thickness of the SCML, $2 \sigma$ ).

et al., 2005; Ardyna et al., 2013). By incorporating the general Gaussian function into the ecosystem dynamical equations, we derive the steady-state solutions for the thickness, depth, and intensity of SCML in various scenarios and examine their dependence on environmental parameters, such as light attenuation coefficient, vertical diffusivity, and sinking velocity of phytoplankton.

\section{Methods}

\subsection{Models}

The SCML occurs below the surface mixed layer, where the light attenuated from above and nutrients supplied from the deep water result in the maximal value of phytoplankton growth rate (Fig. 1). The partial differential equations for 
phytoplankton and nutrients dynamics in which light and nutrients are two major limiting factors (Eqs. 1 and 2) (Riley et al., 1949; Lewis et al., 1986; Gabric and Parslow, 1989; Huisman et al., 2006; Liccardo et al., 2013) were adopted in this study:

$$
\begin{aligned}
& \frac{\partial P}{\partial t}=\mu_{\mathrm{m}} \min (f(I), g(N)) P \\
& -\varepsilon P-w \frac{\partial P}{\partial z}+\frac{\partial}{\partial z}\left(K_{\mathrm{v}} \frac{\partial P}{\partial z}\right), \\
& \frac{\partial N}{\partial t}=-1.59 \mu_{\mathrm{m}} \min (f(I), g(N)) P \\
& +1.59 \alpha \varepsilon P+\frac{\partial}{\partial z}\left(K_{\mathrm{v}} \frac{\partial N}{\partial z}\right),
\end{aligned}
$$

where $P$ denotes the Chl $a$ concentration, $N$ is the limiting nutrient concentration. The photoacclimation of phytoplankton is not considered here and the Chl $a$ distribution is supposed to represent the distribution of phytoplankton biomass. This is a significant simplification. In fact, phytoplankton increases intercellular pigment concentration when light level decreases (Cullen, 1982; Fennel and Boss, 2003). Usually, the unit of Chl $a$ concentration is $\mathrm{mg} \mathrm{m}^{-3}$, the concentrations of phytoplankton and the limiting nutrients are in units of $\mathrm{mmol} \mathrm{N} \mathrm{m}^{-3}$. A ratio of $1.59 \mathrm{~g}$ of chlorophyll per mole of nitrogen (Cloern et al., 1995; Oschlies, 2001) is thereby used for unit conversion. $\mu_{\mathrm{m}}$ is the maximum growth rate of phytoplankton, $\varepsilon$ is the loss rate of phytoplankton (including respiration, mortality, and zooplankton grazing). $\alpha$ is the recycling rate of dead phytoplankton $(0 \leq \alpha \leq 1)$. $w$ is the sinking velocity of phytoplankton, which is non-negative in the chosen coordinate system and assumed to be constant with depth. $K_{\mathrm{v}}$ is the vertical turbulent diffusivity and it is much larger within the surface mixed layer than that beneath. Here, $K_{\mathrm{V}}$ depends on depth in the following way (Hodges and Rudnick, 2004; Mellard et al., 2011):

$K_{\mathrm{v}}= \begin{cases}K_{\mathrm{v} 1} & 0<z<z_{\mathrm{s}} \\ K_{\mathrm{v} 2} & z_{\mathrm{s}}<z<z_{\mathrm{b}}\end{cases}$

where $z_{\mathrm{s}}$ is the depth of surface mixed layer and $z_{\mathrm{b}}$ is the location where the $\mathrm{Chl} a$ concentration reduces to nearly zero in a sufficiently deep water column. We assume $K_{\mathrm{v} 1}$ and $K_{\mathrm{v} 2}$ are constant and $K_{\mathrm{v} 1}$ is large enough to homogenize the Chl $a$ and nutrient concentrations in the surface mixed layer.

A gradual transition from the surface mixed layer to the deep one written in terms of a generalized Fermi function is adopted (Ryabov et al., 2010), that is, $K_{\mathrm{v}}(z)=K_{\mathrm{v} 2}+$ $\frac{K_{\mathrm{v} 1}-K_{\mathrm{v} 2}}{1+e^{(z-z \mathrm{~s}) / l}}$, where parameter $l$ characterizes the width of the transition layer. In our study, we assumed this transition layer is finitely thin.

The growth-limited function $\min (f(I), g(N))$ for light $I$ and nutrients $N$ is

$\min (f(I), g(N))=\min \left(\frac{I(z)}{K_{\mathrm{I}}+I(z)}, \frac{N(z)}{K_{\mathrm{N}}+N(z)}\right)$, where $K_{\mathrm{I}}$ and $K_{\mathrm{N}}$ denote the half-saturation constants of light and nutrients, respectively. The net growth rate, $\mu_{\mathrm{m}} \min (f(I), g(N))-\varepsilon$, is positive only if both the lightlimiting term $\mu_{\mathrm{m}} f(I)$ and nutrient-limiting term $\mu_{\mathrm{m}} g(N)$ are larger than the loss rate $\varepsilon$.

Light intensity is assumed to decrease exponentially with depth according to the Lambert-Beer law, i.e.,

$I(z)=I_{0} \exp \left(-K_{\mathrm{d}} z\right)$,

where $I_{0}$ is the surface light intensity and $K_{\mathrm{d}}$ is the light attenuation coefficient (Morel, 1988). Assuming a constant $K_{\mathrm{d}}$, we ignore the effects of the self-shading and the dissolved and particulate material on the attenuation coefficient.

The zero-flux boundary condition for the phytoplankton at the surface is used. Like the study reported by Ryabov et al. (2010), we also set the chlorophyll concentration approaches to zero at the bottom boundary $z_{\mathrm{b}}$, i.e., $P \rightarrow 0$ for $z \rightarrow z_{\mathrm{b}}$. Fennel and Boss (2003) used an infinite depth as $z_{\mathrm{b}}$. Furthermore, we assume a zero-flux boundary condition for nutrients at the surface, while nutrients are replenished from below. That is,

$$
\left\{\begin{array}{l}
K_{v 1} \frac{\partial P}{\partial z}=0, \quad K_{v 1} \frac{\partial N}{\partial z}=0, \quad \text { at } z=0, \\
P\left(z_{\mathrm{b}}\right)=0, \quad K_{v 2} \frac{\partial N}{\partial z}=\left.K_{v 2} \frac{\partial N}{\partial z}\right|_{z=z_{\mathrm{b}}}, \quad \text { at } z=z_{\mathrm{b}} .
\end{array}\right.
$$

In addition, Lewis et al. (1983) first proposed a general Gaussian distribution function (Eq. 7) to model the nonlinear feature of observed vertical Chl $a$ profiles. In this study, this function is adopted to represent the bell-shaped vertical distribution of Chl $a$ (Fig. 1).

$$
P(z)=P_{\max } e^{-\frac{\left(z-z_{\mathrm{m}}\right)^{2}}{2 \sigma^{2}}} \quad 0 \leq z \leq z_{\mathrm{b}}
$$

where $P(z)$ is Chl $a$ concentration as a function of depth $z$, and $P_{\max }=\frac{h}{\sigma \sqrt{2 \pi}}$. The three Gaussian parameters $\left(h, z_{\mathrm{m}}, \sigma\right)$ can vary to characterize the SCM phenomenon. Thus $h$ is the vertical integrated $\mathrm{Chl} a$ over the entire water column, $z_{\mathrm{m}}$ is the depth of the maximum Chl $a$ (the peak of the bell shape), and $\sigma$ is the standard deviation of the Gaussian function, which controls the thickness of the SCML.

\subsection{Three SCM characteristics}

The thickness of SCML can characterize the vertical extent of Chl $a$ distribution below the surface mixed layer. It is still a matter of debate as how to best define the thickness of SCML. One easy definition is to use the width between two locations below and above the Chl $a$ peak, where Chl $a$ is a certain fraction (e.g., $50 \%, 100\left(e^{-1 / 2}\right) \%$ ) of the maximum Chl $a$ (Platt et al., 1988; Pérez et al., 2006). Some studies bounded the layer by sharp vertical gradients in Chl $a$ above and below the peak (Prairie et al., 2011). Others defined the 
upper and lower boundary of SCML by means of ad hoc choices. Pedrós-Alió et al. (1999) proposed the SCML from the depth of the surface mixed layer to the lower maximum gradient in the slope of the Chl $a$ profile. Hanson et al. (2007) defined that the upper boundary of the SCML was the minimum gradient criterion of $0.02 \mathrm{mg}$ of $\mathrm{Chl} a$ per meter and the lower was the base of the euphotic zone. Beckmann and Hense (2007) proposed to define the boundaries of SCML by the existence of two community compensation depths in the water column, which were located at the depths of two maximum phytoplankton gradients in phytoplankton biomass.

Building on the study by Beckmann and Hense (2007), the locations of the maximum phytoplankton gradients are defined as the boundaries of SCML in this study. That is,

$$
\left.\frac{\mathrm{d}^{2} P}{\mathrm{~d} z^{2}}\right|_{z=z_{u}, z_{1}}=0,
$$

where $z_{\mathrm{u}}$ and $z_{1}$ are the upper and lower boundary of SCML, respectively.

By substituting Eq. (7) into this equality, we obtain $z_{\mathrm{u}}=$ $z_{\mathrm{m}}-\sigma, z_{1}=z_{\mathrm{m}}+\sigma$. Thus, the thickness of SCML can thereby be expressed as $2 \sigma$.

From Eq. (8) and the steady state of Eq. (1), one gets the following equality at the boundaries of SCML:

$$
\left.\left(\mu_{\mathrm{m}} \min (f(I), g(N)) P-\varepsilon P-w \frac{\mathrm{d} P}{\mathrm{~d} z}\right)\right|_{z=z_{u}, z_{1}}=0 .
$$

That is, the boundary of SCML is located at the depth where there is the balance between phytoplankton growth and all losses (including the divergence of the sinking flux $w \frac{\mathrm{d} P}{\mathrm{~d} z}$ and the loss $\varepsilon$ due to mortality, respiration, and grazing), named the community compensation depth (Ono et al., 2001). Thus, this definition reflects the physical-biological ecosystem dynamics associated with SCML.

As described in Eq. (7), the depth of the SCML is defined as $z_{\mathrm{m}}$, that is, the location of the point-wise maximum value of Chl $a$.

The third quantity, i.e., the intensity of SCML, refers to the maximum value of $\mathrm{Chl} a\left(P_{\max }\right.$ in Eq. 7$)$ in the water column.

\subsection{Approach used in this study}

Previous numerical studies (Huisman et al., 2006; Ryabov et al., 2010) showed that the ecosystem dynamical model (Eqs. 1 and 2) can approximately reproduce the bell-shaped feature of the vertical Chl $a$ profile (Fig. 1). We assume a general Gaussian function of $P(z)$ (Eq. 7) is the solution for Eqs. (1) and (2) at steady state to derive explicit relationships between three characteristics of SCM and the environmental parameters. If nutrient input to the mixed layer due to riverine inputs, surface runoff, or atmospheric deposition is considered in the ecosystem, the surface concentration of Chl $a$ should be positive (Mellard et al., 2011). Thus, the general Gaussian function is not an exact solution; at best, it is an approximate solution of the dynamical Eqs. (1) and (2) by ignoring external nutrient input.

Firstly, by substituting the general Gaussian function of $P(z)$ with the steady-state version of Eq. (1), we obtain that, below the surface mixed layer, the net growth rate of phytoplankton can be expressed as follows:

$$
\begin{aligned}
\mu_{\mathrm{m}} \min & (f(I), g(N))-\varepsilon= \\
& -\frac{K_{\mathrm{v} 2}}{\sigma^{4}}\left(z-z_{\mathrm{m}}+\frac{w \sigma^{2}}{2 K_{\mathrm{v} 2}}\right)^{2}+\frac{w^{2}}{4 K_{\mathrm{v} 2}}+\frac{K_{\mathrm{v} 2}}{\sigma^{2}} .
\end{aligned}
$$

Letting $\mu_{\mathrm{m}} \min (f(I), g(N))-\varepsilon=0$, we get the two compensation depths, $z_{\mathrm{c} 1}, z_{\mathrm{c} 2}$, by solving Eq. (10):

$$
\begin{gathered}
z_{\mathrm{c} 1}=z_{\mathrm{m}}-\frac{w \sigma^{2}}{2 K_{\mathrm{v} 2}}-\sqrt{\left(\frac{w \sigma^{2}}{2 K_{\mathrm{v} 2}}\right)^{2}+\sigma^{2}}, \\
z_{\mathrm{c} 2}=z_{\mathrm{m}}-\frac{w \sigma^{2}}{2 K_{\mathrm{v} 2}}+\sqrt{\left(\frac{w \sigma^{2}}{2 K_{\mathrm{v} 2}}\right)^{2}+\sigma^{2}} .
\end{gathered}
$$

From the property of the quadratic function which graph is a parabola and is pointed downward (the right-hand terms in Eq. 10), we know that for $z_{\mathrm{c} 1}<z<z_{\mathrm{c} 2}$ the inequality $\mu_{\mathrm{m}} \min (f(I), g(N))-\varepsilon>0$ is satisfied. This indicates that the subsurface net production occurs only between the two compensation depths where the growth rate $\mu_{\mathrm{m}} \min (f(I), g(N))$ equals the loss rate $\varepsilon$. Beckmann and Hense (2007) found similar results through numerical modeling and emphasized the often overlooked fact that an SCML has to have two compensation depths.

From Eq. (11), we obtain $z_{\mathrm{c} 1} \leq z_{\mathrm{m}}-\sigma$ and $z_{\mathrm{m}} \leq z_{\mathrm{c} 2} \leq$ $z_{\mathrm{m}}+\sigma$ (Fig. 1). In particular, $z_{\mathrm{c} 1}=z_{\mathrm{m}}-\sigma$, and $z_{\mathrm{c} 2}=z_{\mathrm{m}}+\sigma$ when the sinking velocity of phytoplankton $w$ is too small to affect the chlorophyll profile significantly. This result is identical to that of Beckmann and Hense (2007) for neglecting sinking velocity of phytoplankton.

Hence, according to the property of quadratic function, there exists a depth $z_{0}$ between the two compensation depths,

$z_{0}=z_{\mathrm{m}}-\frac{w \sigma^{2}}{2 K_{\mathrm{v} 2}}$

such that the net growth rate of phytoplankton is at its maximum, i.e.,

$\left.\max \left(\mu_{\mathrm{m}} \min (f(I), g(N))-\varepsilon\right)\right|_{z_{0}}=\frac{K_{\mathrm{v} 2}}{\sigma^{2}}+\frac{w^{2}}{4 K_{\mathrm{v} 2}}$.

In other words, the maximum in net growth rates of phytoplankton occurs at the depth of $z_{0}$.

We define $T=\sigma^{2} / K_{\mathrm{v} 2}$ as the characteristic vertical mixing timescale in the SCML of thickness $\sigma$ (Bowdon, 1985; Gabric and Parslow, 1989). Let the length scale be $L=2$ $K_{\mathrm{v} 2} / w$, which determines the scale height of the phytoplankton distribution (Ghosal and Mandre, 2003). Thus, the righthand terms of Eq. (13) can be rewritten as $1 / T+w /(2 L)$. In 
other words, the maximum net growth rate of phytoplankton, $\max \left(\mu_{\mathrm{m}} \min (f(I), g(N))-\varepsilon\right)$, is determined by the vertical mixing timescale $(T)$ and the time taken by a phytoplankton sinking $(w)$ through lengths $(2 L)$.

Equation (12) also shows that $z_{\mathrm{m}} \geq z_{0}$, that is, the depth of SCML lies at or below the depth for phytoplankton having the maximum growth rate. Observations in the Southern California Bight have supported this (Cullen and Eppley, 1981). Particularly, $z_{\mathrm{m}}=z_{0}$ approximately holds when either the sinking velocity $(w)$ or Gaussian parameter $\sigma$ is very small. For non-sinking phytoplankton, i.e., $w \rightarrow 0$, numerical modeling can support this equality (Beckmann and Hense, 2007). When parameter $\sigma$ is assumed to be infinitely thin, the equality is obviously correct, which has been used to solve for the equilibrium depth and intensity of an infinitely thin layer (Klausmeier and Litchman, 2001; Yoshiyama et al., 2009; Mellard et al., 2011).

In this special case $\left(z_{\mathrm{m}}=z_{0}\right)$, some studies found that the depth of SCML is at the location of equal limitation by nutrients and light (Klausmeier and Litchman, 2001; Yoshiyama et al., 2009; Mellard et al., 2011). In this study, we further infer that when $z_{\mathrm{m}}>z_{0}$, the depth of SCML is located where phytoplankton growth is limited by light (Appendix A).

According to Eqs. (12) and (A2), the growth of phytoplankton is light-limited at and below the depth of SCML. Therefore, for $z=z_{\mathrm{m}}$ and $z=z_{\mathrm{m}}+\sigma$, the net growth rate of phytoplankton (Eq. 10) can be respectively expressed as follows:

$\left.\mu_{\mathrm{m}} f(I)\right|_{z=z_{\mathrm{m}}}-\varepsilon=K_{\mathrm{v} 2} / \sigma^{2}$,

$\left.\mu_{\mathrm{m}} f(I)\right|_{z=z_{\mathrm{m}}+\sigma}-\varepsilon=-w / \sigma$.

At the depth of $z_{\mathrm{m}}$, the net growth rate of phytoplankton (Eq. 14) is determined by the vertical mixing time, $T$, while the time taken by phytoplankton sinking through half-length of SCML, $w / \sigma$, controls the net growth rate of phytoplankton (Eq. 15) at the lower boundary of SCML $\left(z_{\mathrm{m}}+\sigma\right)$.

In addition, from Eqs. (12) and (A2) we obtain that the upper compensation depth, $z_{\mathrm{c} 1}$, is the location where the growth limited by nutrients, $\mu_{\mathrm{m}} g(N)$, equals the loss rate, $\varepsilon$, while the lower compensation depth, $z_{\mathrm{c} 2}$, represents the depth where the growth limited by light, $\mu_{\mathrm{m}} f(I)$, equals the loss rate, $\varepsilon$.

\section{Results}

\subsection{Analytic solutions of three SCM characteristics}

By substituting the growth limitation function for light (Eqs. 4 and 5) into Eqs. (14) or (15), we obtain the expression of parameter $z_{\mathrm{m}}$, i.e.,

$z_{\mathrm{m}}=\frac{1}{K_{\mathrm{d}}} \ln \left[\left(\frac{\mu_{\mathrm{m}}}{\varepsilon+K_{\mathrm{v} 2} / \sigma^{2}}-1\right) \frac{I_{0}}{K_{\mathrm{I}}}\right]$ or

$z_{\mathrm{m}}=\frac{1}{K_{\mathrm{d}}} \ln \left[\left(\frac{\mu_{\mathrm{m}}}{\varepsilon-w / \sigma}-1\right) \frac{I_{0}}{K_{\mathrm{I}}}\right]-\sigma$.

The occurrence of an SCM requires $z_{\mathrm{m}}>0$. Requiring a positive solution for Eq. (16), we obtain $\left(\frac{\mu_{\mathrm{m}}}{\varepsilon+K_{\mathrm{v} 2} / \sigma^{2}}-1\right) \frac{I_{0}}{K_{\mathrm{I}}}>$ 1, i.e., $\left(\mu_{\mathrm{m}} f\left(I_{0}\right)-\varepsilon\right) \sigma^{2}>K_{\mathrm{v} 2}$. For any $\sigma>0$, we get $\mu_{\mathrm{m}} f\left(I_{0}\right)>\varepsilon$. That is, the necessary condition for the existence of SCM is $\mu_{\mathrm{m}} f\left(I_{0}\right)>\varepsilon$, which is identical to the result of Fennel and Boss (2003) when vertical sinking is constant as a function of depth in their model.

Subtracting Eqs. (16) and (17), and rearranging, we obtain the expression of parameter $\sigma$ :

$\left(\frac{\mu_{\mathrm{m}}}{\mu_{\mathrm{m}}-\varepsilon+\frac{w}{\sigma}}-1\right) e^{K_{\mathrm{d}} \sigma}=\frac{\mu_{\mathrm{m}}}{\mu_{\mathrm{m}}-\varepsilon-\frac{K_{\mathrm{v} 2}}{\sigma^{2}}}-1$.

Thus far, we have obtained the theoretical relationships between Gaussian parameter $\sigma, z_{\mathrm{m}}$, and environmental parameters (Eqs. 16-18). To derive the relationship between Gaussian parameter $h$ and environmental parameters, we now return to Eqs. (1) and (2). In steady state, adding these two equations leads to

$(1-\alpha) \varepsilon P+w \frac{\mathrm{d} P}{\mathrm{~d} z}=\frac{\mathrm{d}^{2}\left(K_{\mathrm{v}} P\right)}{\mathrm{d} z^{2}}+\frac{1}{1.59} \frac{\mathrm{d}^{2}\left(K_{\mathrm{v}} N\right)}{\mathrm{d} z^{2}}$.

Note that this relationship holds irrespective of the form of growth-limiting function. Integrating this equation from the surface to bottom boundary $\left(z_{\mathrm{b}}\right)$ and using boundary conditions (Eq. 6) gives

$1.59(1-\alpha) \varepsilon \int_{0}^{z_{\mathrm{b}}} P(z) \mathrm{d} z=\left.K_{\mathrm{v} 2} \frac{\mathrm{d} N}{\mathrm{~d} z}\right|_{z=z_{\mathrm{b}}}$.

When the recycling processes do not immediately convert dead phytoplankton back into dissolved nutrients below the surface mixed layer, i.e., $\alpha \neq 1$ (for $\alpha=1$, the detailed derivation for the intensity of SCML is presented in Appendix B), one gets the total Chl $a$ in the water column:

$h=\frac{\left.K_{\mathrm{v} 2} \frac{\mathrm{d} N}{\mathrm{~d} z}\right|_{z=z_{\mathrm{b}}}}{1.59(1-\alpha) \varepsilon}$.

This equality indicates that the total Chl $a$ in the water column $(h)$ is independent of the sinking velocity of phytoplankton. Both Ryabov et al. (2010) and Mellard et al. (2011) obtained a similar result.

The intensity of SCML is

$P_{\max }=\frac{\left.K_{\mathrm{v} 2} \frac{\mathrm{d} N}{\mathrm{~d} z}\right|_{z=z_{\mathrm{b}}}}{1.59 \sqrt{2 \pi} \sigma(1-\alpha) \varepsilon}$.

Obviously, both the total $\mathrm{Chl} a$ in the water column and the intensity of SCML are proportional to the flux of nutrients from below $\left(\left.K_{\mathrm{v} 2} \frac{\mathrm{d} N}{\mathrm{~d} z}\right|_{z=z_{\mathrm{b}}}\right)$, which is determined by the diffusivity below the surface mixed layer and the nutrients gradient at the bottom of water column. Varela et al. (1994) also found a similar result via simulations. 


\subsection{Influences of environmental parameters on SCM characteristics}

We now investigate how the steady-state thickness, depth, and intensity of SCML depend on environmental parameters. Because the analytic solutions for SCML depth and intensity depend on Gaussian parameter $\sigma$ and environmental parameters, we first examine the influence of environmental parameters on parameter $\sigma$.

Equation (18) shows that the thickness of SCML is independent of sea surface light intensity $\left(I_{0}\right)$. This is consistent with numerical simulations (Beckmann and Hense, 2007). This result also suggests that seasonal variation in SCML thickness has no relation to light intensity. Thus, it is not surprising that the empirical model poorly predicted parameter $\sigma$ by using season as an important factor (Richardson et al., 2003).

To illustrate the effects of other model parameters $\left(K_{\mathrm{d}}\right.$, $\left.K_{\mathrm{v} 2}, \mu_{\mathrm{m}}, \varepsilon, w\right)$ on the parameter $\sigma$, we need to obtain informative algebraic expression of $\sigma$. To simplify, by Taylor expansion of $e^{K_{\mathrm{d}} \sigma}$ at $\sigma=0$ and truncating the Taylor series after the linear term, i.e., $e^{K_{\mathrm{d}} \sigma}=1+K_{\mathrm{d}} \sigma+o\left(\sigma^{2}\right)$, Eq. (18) can thereby be rewritten as

$\sigma^{3}-\frac{w}{\varepsilon} \sigma^{2}-\frac{\varepsilon K_{\mathrm{d}} K_{\mathrm{v} 2}+\mu_{\mathrm{m}} w}{\varepsilon K_{\mathrm{d}}\left(\mu_{\mathrm{m}}-\varepsilon\right)} \sigma=\frac{K_{\mathrm{v} 2}\left(\mu_{\mathrm{m}} / K_{\mathrm{d}}-w\right)}{\varepsilon\left(\mu_{\mathrm{m}}-\varepsilon\right)}$.

According to the properties of a cubic function, we know that Eq. (23) has one and only one positive real root $\sigma$, when $\frac{K_{\mathrm{v} 2}\left(\mu_{\mathrm{m}} / K_{\mathrm{d}}-w\right)}{\varepsilon\left(\mu_{\mathrm{m}}-\varepsilon\right)} \geq 0$. Because $\mu_{\mathrm{m}} f\left(I_{0}\right)>\varepsilon$ and $0<f\left(I_{0}\right)<1, \mu_{\mathrm{m}}>\varepsilon$. Thus, when the maximum phytoplankton growth rate $\left(\mu_{\mathrm{m}}\right)$ within one penetration depth $\left(1 / K_{\mathrm{d}}\right)$ is larger than sinking velocity of phytoplankton, i.e., $\mu_{\mathrm{m}} / K_{\mathrm{d}}-w \geq 0$, there exists a non-negative value of parameter $\sigma$, which increases with increasing $\frac{K_{\mathrm{v} 2}\left(\mu_{\mathrm{m}} / K_{\mathrm{d}}-w\right)}{\varepsilon\left(\mu_{\mathrm{m}}-\varepsilon\right)}$.

Using dimensional analysis, Klausmeier and Litchman (2001) found that the degree of turbulence determines the thickness of SCML. Our analytical result shows that the thickness of SCML increases with increasing vertical diffusivity below the surface mixed layer $\left(K_{\mathrm{v} 2}\right)$. In addition, the SCML thickness decreases with increasing sinking velocity of phytoplankton $(w)$ and light attenuation coefficient $\left(K_{\mathrm{d}}\right)$.

The right-hand term in Eq. (23), $\frac{K_{\mathrm{v} 2}\left(\mu_{\mathrm{m}} / K_{\mathrm{d}}-w\right)}{\varepsilon\left(\mu_{\mathrm{m}}-\varepsilon\right)}$, can be modified to $\frac{K_{\mathrm{v} 2}\left(\mu_{\mathrm{m}} / K_{\mathrm{d}}-w\right)}{-\left(\varepsilon-\mu_{\mathrm{m}} / 2\right)^{2}+\mu_{\mathrm{m}}^{2} / 4}$. Thus, the effect of loss rate $(\varepsilon)$ on parameter $\sigma$ depends on $\mu_{\mathrm{m}} / 2$. Note that $\mu_{\mathrm{m}} f\left(I_{0}\right)>\varepsilon$ once the SCM occurs. When the surface light intensity $I_{0}$ is smaller than or equal to the half-saturation constant for light $K_{\mathrm{I}}$, i.e., $f\left(I_{0}\right) \leq 0.5$, then $0<\varepsilon<\mu_{\mathrm{m}} f\left(I_{0}\right) \leq \mu_{\mathrm{m}} / 2$; thus $\sigma$ decreases with increasing $\varepsilon$. Conversely, when $f\left(I_{0}\right)>0.5$, for $\varepsilon \geq \mu_{\mathrm{m}} / 2, \sigma$ increases with increasing $\varepsilon$; for $\varepsilon<\mu_{\mathrm{m}} / 2$, $\sigma$ decreases with increasing $\varepsilon$. In summary, for smaller loss rates $\left(\varepsilon<\mu_{\mathrm{m}} / 2\right)$, decreased $\varepsilon$ leads to a thicker SCML, while for larger loss rates $\left(\varepsilon \geq \mu_{\mathrm{m}} / 2\right)$, decreased $\varepsilon$ leads to a thinner SCML.
Equation (16) can be rewritten as

$z_{\mathrm{m}}=\frac{1}{K_{\mathrm{d}}} \ln \left(A I_{0}\right)$,

where $A=\frac{1}{K_{\mathrm{I}}}\left(\frac{\mu_{\mathrm{m}}}{\varepsilon+K_{\mathrm{v} 2} / \sigma^{2}}-1\right)$. Clearly, from Eq. (18) we know $A$ does not depend on surface light intensity $\left(I_{0}\right)$; thus we infer that the depth of SCML increases logarithmically with increasing $I_{0}$. In other words, the SCML gets deeper due to the seasonal increase in $I_{0}$ and remains almost unchanged when the surface light intensity increases to a certain degree. Observations at the HOT (Hawaii Ocean Time-series) site in the eastern Pacific and the SEATS (South East Asia Timeseries Station) station in the South China Sea showed a significant seasonal variation in SCML depth (Chen et al., 2006; Hense and Beckmann, 2008). Hense and Beckmann (2008) explained the deepening of SCML depth in spring at the HOT site by the seasonal increase in the light intensity. Modeling sensitivity analyses also showed that an increase in the surface light intensity yields a deeper SCML (Jamart et al., 1979; Varela et al., 1994; Beckmann and Hense, 2007).

Determining the effect of vertical diffusivity below the surface mixed layer $\left(K_{\mathrm{v} 2}\right)$ on the steady-state SCML intensity is more difficult. Increased $K_{\mathrm{v} 2}$ increases parameter $\sigma$ (Eq. 23) and the diffusive flux of nutrients from below (Eq. 22); however, this parameter has opposite effects on $P_{\max }$ (Eq. 22). With Eq. (23) rearranged we obtain

$$
\begin{aligned}
& \frac{K_{\mathrm{v} 2}}{\sigma}=\frac{\left(\mu_{\mathrm{m}}-\varepsilon\right) \varepsilon}{\left(\mu_{\mathrm{m}} / K_{\mathrm{d}}-w\right) / \sigma^{2}+\varepsilon / \sigma} \\
& +\frac{\left(\mu_{\mathrm{m}}-\varepsilon\right) w}{\left(\mu_{\mathrm{m}} / K_{\mathrm{d}}-w\right) / \sigma+\varepsilon} \\
& -\frac{\mu_{\mathrm{m}} w / K_{\mathrm{d}}}{\mu_{\mathrm{m}} / K_{\mathrm{d}}-w+\varepsilon \sigma} .
\end{aligned}
$$

Clearly, all the three terms on the right-hand side of this equality increase due to the increasing $\sigma$ by a higher $K_{\mathrm{v} 2}$. Therefore, it can be inferred that increased vertical diffusivity below the surface mixed layer $\left(K_{\mathrm{v} 2}\right)$ leads to a stronger SCML intensity $\left(P_{\max }\right)$.

The influences of various parameters on SCM characteristics determined by Eqs. (16-18), (21), and (22) are summarized in Table 1. For example, increased light levels (increasing surface light intensity $I_{0}$, decreasing attenuation coefficient $K_{\mathrm{d}}$ ) or increased light competitive ability (decreasing half-saturation constant for light $K_{\mathrm{I}}$ ) moves the SCML deeper; increased nutrient supply (increasing vertical diffusivity below the surface mixed layer $K_{\mathrm{v} 2}$ and loss rate of phytoplankton $\varepsilon$ ) moves the layer toward the surface. The shape of SCML (thickness and intensity) is mainly influenced by nutrient supply $\left(K_{\mathrm{v} 2}\right.$ and $\varepsilon$ ). The intensity of SCML becomes weaker as a result of expanding the SCML by a lower sinking velocity of phytoplankton $(w)$ and a smaller light attenuation coefficient $\left(K_{\mathrm{d}}\right)$. 
Table 1. Influences of dynamic model parameters on the steady-state SCML thickness $(2 \sigma)$, depth $\left(z_{\mathrm{m}}\right)$, intensity $\left(P_{\max }\right)$, and the total Chl $a$ in the water column $(h)$.

\begin{tabular}{|c|c|c|c|c|}
\hline Model parameters $(\uparrow)$ & $2 \sigma$ & $z_{\mathrm{m}}$ & $P_{\max }$ & $h$ \\
\hline $\begin{array}{l}I_{0} \\
\text { (photosynthetically available radiation) }\end{array}$ & - & $\uparrow$ & - & - \\
\hline $\begin{array}{l}K_{\mathrm{I}} \\
\text { (half-saturation constant of light-limited growth) }\end{array}$ & - & $\downarrow$ & - & - \\
\hline $\begin{array}{l}K_{\mathrm{v} 2} \\
\text { (vertical diffusivity below surface mixed layer) }\end{array}$ & $\uparrow$ & $\downarrow$ & $\uparrow$ & $\uparrow$ \\
\hline $\begin{array}{l}w \\
\text { (sinking velocity of phytoplankton) }\end{array}$ & $\downarrow$ & $\downarrow$ & $\uparrow$ & - \\
\hline $\begin{array}{l}K_{\mathrm{d}} \\
\text { (light attenuation coefficient) }\end{array}$ & $\downarrow$ & $\downarrow$ & $\uparrow$ & - \\
\hline \multirow{2}{*}{$\begin{array}{l}\varepsilon \\
\text { (loss rate of phytoplankton) }\end{array}$} & $\downarrow *$ & $\downarrow$ & / & $\downarrow$ \\
\hline & $\uparrow * *$ & $\downarrow$ & $\downarrow$ & $\downarrow$ \\
\hline $\begin{array}{l}\alpha \\
\text { (nutrient recycling coefficient) }\end{array}$ & - & - & $\uparrow$ & $\uparrow$ \\
\hline $\begin{array}{l}\left.\frac{\mathrm{d} N}{\mathrm{~d} z}\right|_{z=z_{\mathrm{b}}} \\
\text { (nutrient gradient at the lower boundary of SCML) }\end{array}$ & - & - & $\uparrow$ & $\uparrow$ \\
\hline $\begin{array}{l}K_{\mathrm{N}} \\
\text { (half-saturation constant of nutrient limited growth) }\end{array}$ & - & - & - & - \\
\hline $\begin{array}{l}K_{\mathrm{v} 1} \\
\text { (vertical diffusivity in surface mixed layer) }\end{array}$ & - & - & - & - \\
\hline $\begin{array}{l}\mu_{\max } \\
\text { (maximum growth rate of phytoplankton) }\end{array}$ & l & / & / & l \\
\hline
\end{tabular}

$\uparrow$ indicates increase, $\downarrow$ indicates decrease, - indicates no effect, / indicates no straightforward result, ${ }^{*}$ indicates a result when

$\varepsilon<\mu_{\max } / 2$, and $* *$ indicates a result when $\varepsilon>\mu_{\max } / 2$.

\section{Discussion}

Considering the two-compartment system (nutrients and $\mathrm{Chl} a$ ) in steady state and a general Gaussian function for vertical Chl $a$ concentration, we derived the analytical solution for the fundamental relationships between SCM characteristics and various parameters. Three special scenarios, their limitations, and the implications for this study are discussed below.

\subsection{Three special scenarios}

Equation (18) indicates that the parameter $\sigma$ is affected by changes in the vertical diffusivity below the surface mixed layer $\left(K_{\mathrm{v} 2}\right)$, the sinking velocity of phytoplankton $(w)$ and the light attenuation coefficient $\left(K_{\mathrm{d}}\right)$, which inversely affects depth and intensity of SCML (Eqs. 16, 17, and 22). Thus, three special situations of the theoretical solutions for SCM characteristics are discussed below.
Firstly, the term $K_{\mathrm{v} 2} / \sigma^{2}$ on the right-hand side of Eq. (18) is neglected. This special situation occurs either when the vertical diffusivity below the surface mixed layer is too small to be considered ( $K_{\mathrm{v} 2} \rightarrow 0$ ) or when $K_{\mathrm{v} 2} / \sigma^{2}$ is much smaller than $\mu_{\mathrm{m}}-\varepsilon$, i.e., the mixing timescale $\left(T=\sigma^{2} / K_{\mathrm{v} 2}\right)$ below the surface mixed layer is much longer than the time taken by net growth of phytoplankton, $\left(\mu_{\mathrm{m}}-\varepsilon\right)^{-1}$. Indeed, in the seasonal thermocline, vertical turbulent diffusive timescales can vary from weeks to months for phytoplankton displacements as small as several meters (Denman and Gargett, 1983). The value of $\left(\mu_{\mathrm{m}}-\varepsilon\right)^{-1}$ used in many studies is usually from 0.1 to 5 days (Gabric and Parslow, 1989; Klausmeier and Litchman, 2001; Huisman et al., 2006).

In this situation, from Eq. (14), the growth rate at SCML depth can be expressed as

$\left.\mu_{\mathrm{m}} f(I)\right|_{z=z_{\mathrm{m}}}=\varepsilon$.

In regions with a low vertical diffusivity, Fennel and Boss (2003) derived that, at the SCML depth, the growth 
rate of phytoplankton is equal to the loss rate and the divergence of phytoplankton due to changes in the sinking velocity. Clearly, Eq. (26) is identical to that of Fennel and Boss (2003) for constant sinking velocity of phytoplankton.

In this situation, the depth of SCML can be derived from Eq. (16), i.e.,

$z_{\mathrm{m}}=\frac{1}{K_{\mathrm{d}}} \ln \frac{\left(\mu_{\mathrm{m}}-\varepsilon\right) I_{0}}{\varepsilon K_{\mathrm{I}}}$.

This equality indicates the SCML depth is directly proportional to the light penetration depth $\left(1 / K_{\mathrm{d}}\right)$. Observations by four Bio-Argo floats in the North Pacific Subtropical Gyre, the South Pacific Subtropical Gyre, the Levantine Sea, and in the northwestern Mediterranean Sea showed a significant positive linear relationship between the two variables (Mignot et al. 2014). Beckmann and Hense (2007) also found a similar result through statistical analysis of numerical modeling.

The right-hand term of Eq. (27) can be rewritten as $\frac{1}{K_{\mathrm{d}}} \ln \frac{I_{0}}{I^{*}}$ by letting $I^{*}=\frac{\varepsilon K_{\mathrm{I}}}{\mu_{\mathrm{m}}-\varepsilon}$, where $\mu_{\mathrm{m}} f\left(I^{*}\right)=\varepsilon$. Under the assumption of infinitely thin SCML $(\sigma \rightarrow 0)$, Klausmeier and Litchman (2001) also derived Eq. (27) by setting the vertical diffusivity for phytoplankton to zero, i.e., $K_{\mathrm{V}}=0$, in poorly mixed waters. Here, we go further to obtain the approximate expression of the thickness of SCML from Eq. (23), that is,

$2 \sigma=\frac{w}{\varepsilon}+\sqrt{\left(\frac{w}{\varepsilon}\right)^{2}+\frac{w}{K_{\mathrm{d}}\left(\varepsilon-\varepsilon^{2} / \mu_{\mathrm{m}}\right)}}$.

Obviously, the thickness of SCML increases with an increase in the sinking velocity of phytoplankton $(w)$, and with a decrease in the maximal growth rate $\left(\mu_{\mathrm{m}}\right)$ and the light attenuation coefficient $\left(K_{\mathrm{d}}\right)$.

The second special situation occurs when the term $w / \sigma$ on the left-hand side of Eq. (18) is neglected. This special case occurs in regions where phytoplankton sinking velocity is very low $(w \rightarrow 0)$, or when $w / \sigma$ is much smaller than $\mu_{\mathrm{m}}-\varepsilon$, i.e., the time taken by phytoplankton sinking through half-length of SCML, $(w / \sigma)^{-1}$, is much longer than the time taken by net growth of phytoplankton, $\left(\mu_{\mathrm{m}}-\varepsilon\right)^{-1}$. Phytoplankton sinking velocities exhibit a range of values depending on physical and physiological phenomena (e.g., size and shape of the cell). In the environment, estimates of sinking velocity vary from 0 to $9 \mathrm{~m}$ per day (Gabric and Parslow, 1989; Huisman and Sommeijer, 2002). Thus, the latter special scenarios (i.e., $w / \sigma \ll \mu_{\mathrm{m}}-\varepsilon$ ) can indeed occur.

In this situation, according to Eq. (15), the net growth rate at the lower boundary of SCML can be expressed as

$\left.\mu_{\mathrm{m}} f(I)\right|_{z=z_{\mathrm{m}}+\sigma}-\varepsilon=0$.

That is, the lower boundary of SCML, $z_{\mathrm{m}}+\sigma$, is located at the compensation depth.
In this situation, the depth of SCML can be derived from Eq. (17), i.e.,

$z_{\mathrm{m}}=\frac{1}{K_{\mathrm{d}}} \ln \frac{\left(\mu_{\mathrm{m}}-\varepsilon\right) I_{0}}{\varepsilon K_{\mathrm{I}}}-\sigma$.

Compared with Eq. (27), we know that the depth of SCML is shallower in this special case than that in the case of neglecting the influence of vertical diffusivity below the surface mixed layer on SCM. This result implies that the displacement $(\sigma)$ of SCML depth is the result of combined influences of vertical diffusivity and sinking velocity of phytoplankton.

In this situation, from Eq. (23), we have

$$
\begin{gathered}
\sigma\left(\sigma+\sqrt{\frac{K_{v 2}}{\mu_{\mathrm{m}}-\varepsilon}}\right)\left(\sigma-\sqrt{\frac{K_{v 2}}{\mu_{\mathrm{m}}-\varepsilon}}\right)= \\
\frac{\mu_{\mathrm{m}} K_{v 2}}{\left(\mu_{\mathrm{m}}-\varepsilon\right) \varepsilon K_{\mathrm{d}}} .
\end{gathered}
$$

The SCML thickens with a larger vertical diffusivity below the surface mixed layer $\left(K_{\mathrm{v} 2}\right)$, a smaller growth rate $\left(\mu_{\mathrm{m}}\right)$, or a lower light attenuation coefficient $\left(K_{\mathrm{d}}\right)$. In particular, when $K_{v 2}=0$, we have $\sigma=0$. In other words, for non-sinking phytoplankton $(w \rightarrow 0)$, when the vertical diffusivity below the surface mixed layer is very small $\left(K_{v 2} \rightarrow 0\right)$, the SCML disappears. This indicates that there must be a vertical diffusion window sustaining non-sinking phytoplankton species in deep waters.

The third special situation occurs when $K_{\mathrm{d}} \sigma$ (i.e., $\left.\sigma /\left(K_{\mathrm{d}}\right)^{-1}\right)$ is too small to be considered in Eq. (18). This may occur in clear waters where the light attenuation coefficient is very small $\left(K_{\mathrm{d}} \rightarrow 0\right)$, or in regions where the light penetration depth $\left(1 / K_{\mathrm{d}}\right)$ is much larger than a half-width of $\operatorname{SCML}(\sigma)$. Very narrow (from several to tens of centimeters) SCML has been observed in clear, stratified lakes where the light penetration depths were from several to tens of meters (Fee, 1976; Camacho, 2006).

In this situation, Eq. (18) can be modified to

$w \sigma+K_{\mathrm{v} 2}=0$.

Clearly, when $K_{v 2}=0, w=0$, this equation has infinitely many solutions. This means that, in stable, clear waters with a predominance of small cells, the deep SCML can occur with different thicknesses. For example, in the basin of South China Sea, phytoplankton $<3 \mu \mathrm{m}$ (such as Prochlorococcus, Synechococcus, picoeukaryotes, etc.) are the dominant species in SCMLs (Takahashi and Hori, 1984; Liu et al., 2007) with variable thicknesses (Lee Chen, 2005; Chen et al., 2006).

\subsection{Limitations and potential application}

To make the complex problem (SCM phenomenon) tractable, the ecosystem dynamical equations adopted in this study are judiciously simplified. For example, a constant eddy diffusivity is assumed in the surface mixed layer and below 
this layer, respectively. Many processes (turbulence, internal waves, storms, and slant-wise and vertical convection) in upper ocean dynamics are not captured in the model system. The assumption of steady state will be broken during episodic events of strong physical forcing, nutrient injection, or blooms (Fennel and Boss, 2003). Similarly the biological representation is also extremely limited. We neglect food-web and microbial loop dynamics (detritus, dissolved organic matter, and zooplankton are not included explicitly), and assume all loss processes, except sinking, to be linearly proportional to phytoplankton. The sinking velocity of phytoplankton is assumed to be constant with depth, excluding the effects of temperature and density gradients. Our model also neglects some feedback mechanisms, like the effect of phytoplankton on light attenuation. Although these are important aspects, their addition is unlikely to change our conclusions qualitatively under the boundary conditions chosen in this study (Fennel and Boss, 2003).

Without considering nutrient input directly to the surface mixed layer, Chl $a$ concentration within it is assumed to be nearly zero. The SCML is assumed to occur significantly deeper than the base of surface mixed layer, and the vertical gradient of Chl $a$ is assumed to be identically zero at the transition between the two layers. This vertical profile of Chl $a$ (Fig. 1) is assumed to be well fitted by a general Gaussian function (Eq. 7), in which Chl $a$ within the surface mixed layer is an approximation for the tail of Gaussian function. The Gaussian assumption leads to the results that the vertical diffusivity within the surface mixed layer has no role in the SCM. However, the assumption of a general Gaussian profile can be broken in several ways. If nutrient is directly input into the mixed layer due to riverine inputs, surface runoff, or atmospheric deposition, a positive $\mathrm{Chl} a$ concentration within the surface mixed layer will be sustained (Mellard et al., 2011). In this case, the general Gaussian function can be modified with a superimposition of a background which is either a constant (Platt et al., 1988; Richardson et al., 2003) or a function of water depth (Uitz et al., 2006; Mignot et al., 2011). If the depth of surface mixed layer $z_{\mathrm{s}}$ is large, this allows another way for the surface Chl $a$ concentration to be positive by extracting some of the Chl $a$ from the SCML (Beckman and Hense, 2007); thus the vertical gradient of Chl $a$ may not be identically zero at the transition between the two layers.

Under the assumption of a constant loss rate, the lower compensation depth we obtained from Eq. (11) - the location where the growth rate of phytoplankton limited by light equals the loss rate - is similar to the popular definition of compensation depth given by Sverdrup (1953), below which no net growth occurs. This assumption is in the heart of the Sverdrup's critical depth model and we now understand that it has significant limitations (Behrenfeld and Boss, 2014). Particularly, the treatment of grazing loss is, at the very least, an oversimplification, though many numerical models have used a similar one (e.g., Klausmeier and Litchman, 2001;
Fennel and Boss, 2003; Huisman et al., 2006). Grazing loss depends strongly on phytoplankton and zooplankton concentrations (it is an encounter-based process) and, given that zooplankton can move or, at least, grow faster where more food is available, is unlikely to have a constant concentration distribution (Behrenfeld and Boss, 2014).

Our model suggests that the condition for the existence of an SCM is that the growth rate under the limitation of light intensity, $\mu_{\mathrm{m}} f\left(I_{0}\right)$, is larger than the loss rate, $\varepsilon$, in stratified water columns. Fennel and Boss (2003) found a similar result and pointed out that this condition for an SCM is general. Many numerical studies have reproduced the SCM phenomenon, of which the condition of SCM occurrence met with variable values of the sinking velocity of phytoplankton and the mixing diffusivity (Klausmeier and Litchman, 2001; Huisman et al., 2006; Mellard et al., 2011).

Our two-compartment system model reproduces some of the results of the more complex model with three compartments (phytoplankton, nutrients, and detritus; Beckmann and Hense, 2007). For example, our model predicts that, with full recycling of the dead phytoplankton, the total Chl $a$ concentration in water columns depends on the sinking velocity of phytoplankton and the vertical diffusivity but is independent of the growth rate and the loss rate of phytoplankton. Beckmann and Hense (2007) found similar results. Here, we go further to point out an interesting finding that the derivations of the total Chl $a$ independent of the form of the growthlimiting function. Since growth functional forms in phytoplankton models are still debated in the literature (Haney, 1996; Ayata et al., 2013), this will be most helpful to estimate the vertical integrated $\mathrm{Chl} a$ and primary production.

The relationships (in previous sections and in Appendices $\mathrm{A}$ and $\mathrm{B}$ ) we derived can be used to compute missing model parameters (such as maximum growth rate $\mu_{\mathrm{m}}$, loss rate $\varepsilon$, recycling rate $\alpha$ ) which are difficult to obtain through on-site observation if estimates of others are available. For example, Eq. (B4) allows us to obtain an estimate of the sinking velocity of phytoplankton from the measurement of SCM thickness and intensity, the nutrient concentration at water column depth, and the vertical diffusivity below the surface mixed layer.

Our analytic solutions can in principle be tested through a comparison with observations: for example, the shape of profiles (the SCML thickness, depth, and intensity), expressed by the characteristic relationships (Eqs. 16-18, 22, and B4), the vertical integral of total subsurface $\mathrm{Chl} a$ concentration (Eqs. 21 and B3), the consistency of independent field estimates for sinking velocity, vertical diffusivity, recycling rate, and loss rate (Eqs. 21-22 and B3-B4).

We retrieve the three SCM characteristics from Eqs. (1618 ) and (22) by combining remote sensing data (annual averaged values of surface light intensity $I_{0}$ and light attenuation coefficient $K_{\mathrm{d}}$ ) and some parameters from published field and numerical studies (e.g., sinking velocity of phytoplankton $w$, vertical diffusivity below the surface mixed 
Table 2. Parameter values at SEATS, HOT, and BATS.

\begin{tabular}{lllll}
\hline Parameters & Units & Values at stations & & \\
& & SEATS & HOT & BATS \\
\hline$I_{0}$ & $\mu \mathrm{mol}^{-1}$ photon $\mathrm{m}^{-2} \mathrm{~s}^{-1}$ & $700^{(1,2)}$ & $550^{(1,3)}$ & $448^{(1,4)}$ \\
$K_{\mathrm{d}}$ & $\mathrm{m}^{-1}$ & $0.052^{(1,5)}$ & $0.04^{(1,3)}$ & $0.042^{(1,4)}$ \\
$K_{\mathrm{v} 2}$ & $\mathrm{~m}^{2} \mathrm{~s}^{-1}$ & $5 \times 10^{-5(6)}$ & $5 \times 10^{-5(3)}$ & $1 \times 10^{-4(7,8)}$ \\
$\mu_{\mathrm{max}}$ & $\mathrm{d}^{-1}$ & $1.2^{(9,10)}$ & $0.96^{(3)}$ & $1^{(11)}$ \\
$K_{\mathrm{I}}$ & $\mu \mathrm{mol}^{(1)}$ & $20^{(3)}$ & $20^{(3,12,13)}$ \\
$\varepsilon$ & $\mathrm{d}^{-1}$ & $40^{(12)}$ & $0.24^{(3)}$ & $0.5^{(14)}$ \\
$\alpha$ & - & $0.5^{(9,10)}$ & $0.5^{(3)}$ & $0.16^{(8)}$ \\
$w$ & $\mathrm{md}^{-1}$ & $0.3^{(10)}$ & $1^{(3,15)}$ & $2^{(8)}$ \\
$\mathrm{d} N / \mathrm{d} z$ at depth of $z_{\mathrm{b}}$ & $\mathrm{mmol} \mathrm{N} \mathrm{m}^{-4}$ & $0 . \mathrm{s}^{(14)}$ & $0.05^{(17,18)}$ & $0.02^{(19,20)}$ \\
$z_{\mathrm{b}}$ & $m$ & 200 & 200 & 200 \\
\hline
\end{tabular}

Superscript numbers in parentheses refer to the references that provide the source for the parameter value, and the citations are as follows: (1) http://oceandata.sci.gsfc.nasa.gov/SeaWiFS/Mapped/Annual/9km/; ${ }^{(2)} \mathrm{Wu}$ and Gao, 2011; (3) Huisman et al., 2006; ${ }^{(4)}$ Varela et al., 1994; (5) Lee Chen et al., 2005; (6) Lu et al., 2010; ${ }^{(7)}$ Hood et al., 2001; ( ${ }^{(8)}$ Salihoglu et al., 2008; (9) Cai et al., 2006; ${ }^{(10)}$ Liu et al., 2007; (11) Ayata et al., 2013; (12) Raven and Richardson, 1986; (13) Mara On and Holligan, 1999; (14) Tjiputra et al., 2007; (15) Bienfang and Harrison, 1984; (14) Chen et al., 2006; (15) Fennel and Boss, 2003; (16) Hense and Beckmann, 2008; (17) Cianca et al., 2007; ${ }^{(18)}$ Cianca et al., 2012.

layer $K_{\mathrm{v} 2}$, loss rate $\varepsilon$, maximum growth rate $\mu_{\mathrm{m}}$ ). Table 2 lists the values of model parameters at three time-series stations in different ocean regions, i.e., the SEATS, HOT, and BATS stations (Bermuda Atlantic Time-Series Study) site in the Sargasso Sea, as well as the corresponding references. The estimated results and the observed values of the SCML thickness, depth, and intensity at the three stations are shown in Fig. 2.

The estimated depths and thicknesses of the SCML agree reasonably well with the observations at all three stations. However, the intensities of the SCML are poorly estimated, implying other mechanisms (e.g., wind-driven nutrient pulse) supplying nutrients for the SCML, except upward diffusivity, for phytoplankton growth (Williams et al., 2013). This is the first attempt to estimate the depth, thickness, and intensity of the SCML using parameters from satellite data and field studies. It should be noted that the estimation is sensitive to the values of these environmental parameters used. The values used in estimations above are representative for the averages over a large spatial or temporal scale, but they may not reflect the real values at a specific station. Even though disagreements could be associated with uncertainties from several sources, this type of attempt would give some idea of how real-world data could be incorporated into the model and thus be applied to the field (Pitarch et al., 2014).

\section{Summary}

A general Gaussian function is assumed to represent a bellshaped vertical distribution of Chl $a$ in stratified water columns. The function is incorporated into the ecosystem dynamical equations to determine three steady-state SCM characteristics and examine their dependence on environmental parameters such as vertical diffusivity, sinking velocity of phytoplankton, and light attenuation coefficient.

The maximum $\mathrm{Chl} a$ concentration occurs at or below the location of the maximum growth rates of phytoplankton determined by the vertical mixing timescale and the time taken by a phytoplankton sinking through the length scale.

The depth of the SCML in steady state deepens logarithmically with an increase in surface light intensity but shoals with increasing light attenuation coefficient, increasing vertical diffusivity below the surface mixed layer, increasing loss rate of phytoplankton, and decreasing sinking velocity of phytoplankton.

The thickness and intensity of the SCML are mainly influenced by nutrient supply but are independent of sea surface light intensity. The SCML gets thicker and stronger with a higher vertical diffusivity below the surface mixed layer. The intensity of SCML in steady state weakens as a result of expanding the SCML by a smaller sinking velocity of phytoplankton and a lower light attenuation coefficient.

In regions with a low vertical diffusivity, the SCML depth is inversely proportional to light attenuation coefficient and is deeper than that in regions dominated by non-sinking phytoplankton. In clear and stable waters with a predominance of small cells, deeper SCMLs can occur with different thicknesses. 


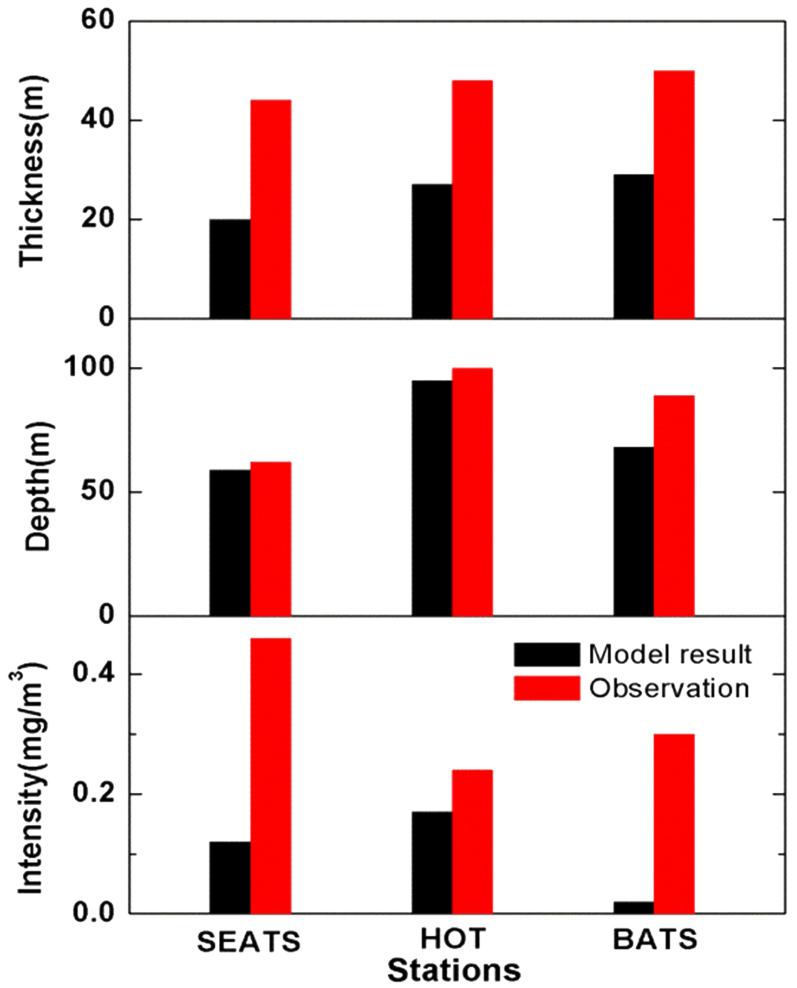

Figure 2. Comparisons of the model results and observations (in terms of thickness, depth, and intensity of SCML) at SEATS, HOT, and BATS (black columns represent the model results and red columns are the observations at the three stations which were fitted via a Gaussian function using annually averaged data obtained from http://www.odb.ntu.edu.tw/, http://hahana.soest. hawaii.edu/hot/hot-dogs/cextraction.html, and http://bats.bios.edu/, respectively).

Upon potential risk of climate change, it is critical to accurately estimate the global and regional SCML-related primary production. However, the SCM characteristics cannot be detected by remote sensing satellites, which will restrict the application of satellite data in estimating primary production in a large temporal and spatial scale. The Argo float equipped with optical sensor has been developed to measure the distribution of particles and chlorophyll in the world's ocean (Mignot et al., 2014), but the data are still limited. The relationships we derived might help to estimate depth-integrated primary production using available data from satellite observations (incident light and light attenuation coefficient) when appropriate vertical estimates of growth rate and loss rate of phytoplankton, sinking velocity of phytoplankton, and vertical diffusivity were adopted based on observations or model results. Again, the solutions could also help to compute environmental parameters that are difficult to obtain from on-site observation. 


\section{Appendix A}

In steady state, the net nutrient flux at any given depth $(z)$ is equal to the net nutrients consumption by phytoplankton; thus from the steady state of Eq. (2) we obtain Eq. (A1) below the surface mixed layer:

$\left.\int\left(\mu_{\mathrm{m}} \min (f(I), g(N))-\alpha \varepsilon\right) P(z) \mathrm{d} z \approx K_{\mathrm{v} 2} \frac{\mathrm{d} N(z)}{\mathrm{d} z}\right|_{z}$.

If $\mu_{\mathrm{m}} \min (f(I), g(N))-\varepsilon>0$, then $\mu_{\mathrm{m}} \min (f(I), g(N))-$ $\alpha \varepsilon>0$ for $0<\alpha \leq 1$, and thus we will have $\frac{\mathrm{d} N}{\mathrm{~d} z}>0$. That is, $N(z)$ will increase with depth below the surface mixed layer.

From the properties of the quadratic function on the righthand side of Eq. (10), we have $\mu_{\mathrm{m}} \min (f(I), g(N))-\varepsilon>0$ in the interval $\left(z_{\mathrm{c} 1}, z_{\mathrm{c} 2}\right)$. Hence, we have $\mu_{\mathrm{m}} \min (f(I), g(N))-$ $\alpha \varepsilon>0$ for $0<\alpha \leq 1$; thus $\mathrm{d} N / \mathrm{d} z>0$. In other words, $N(z)$ increases with depth in the interval $\left(z_{\mathrm{c} 1}, z_{\mathrm{c} 2}\right)$.

According to Eq. (4), we know that $g(N)$ is a monotonically increasing function on interval $\left(z_{\mathrm{c} 1}, z_{\mathrm{c} 2}\right)$ and $f(I)$ is a monotonically decreasing function on interval $\left(z_{\mathrm{c} 1}, z_{\mathrm{c} 2}\right)$. It is well known that the stable SCML occurs in stratified water column only when the growth of phytoplankton in the surface mixed layer is nutrient-limited (Mellard et al., 2011; Ryabov et al., 2010). In other words, the limitation by nutrients $g(N)$ is less than the limitation by light $f(I)$ within the surface mixed layer, i.e., $g(N)<f(I)$ for $0 \leq z \leq z_{\mathrm{s}}$.

Because there is only one maximum in the growth rates of phytoplankton which occurs at the depth $z_{0}=z_{\mathrm{m}}-\frac{w \sigma^{2}}{2 K_{\mathrm{v} 2}}$, and $z_{\mathrm{c} 1}<z_{0}<z_{\mathrm{c} 2}$ (Eq. 11), we arrive at

$\min (f(I), g(N))= \begin{cases}g(N) & z_{\mathrm{c} 1} \leq z \leq z_{0} \\ f(I) & z_{0} \leq z \leq z_{\mathrm{c} 2}\end{cases}$

and

$\max \left(\mu_{\mathrm{m}} \min (f(I), g(N))\right)=\left.\mu_{\mathrm{m}} f(I)\right|_{z=z_{0}}$.

That is, the maximum growth rate occurs at the depth $z_{0}$, where there is a transition from nutrient limitation to light limitation, thus the growth of phytoplankton is light-limited below the depth $z_{0}$.

\section{Appendix B}

The dead phytoplankton is entirely recycled $(\alpha=1)$, and thus the system is closed. In this case, at steady state, Eq. (19) reduces to

$w \frac{\mathrm{d} P}{\mathrm{~d} z}=\frac{\mathrm{d}^{2}}{\mathrm{~d} z^{2}}\left(K_{\mathrm{v}}(P+N)\right)$.

Integrating this equation twice from the surface to bottom boundary $\left(z_{\mathrm{b}}\right)$ gives

$w \int_{0}^{z \mathrm{~b}} P(z) d z=\left.K_{\mathrm{v} 1}(P+N)\right|_{0} ^{z_{\mathrm{s}}}+\left.K_{\mathrm{v} 2}(P+N)\right|_{z_{\mathrm{s}}+0} ^{z_{\mathrm{b}}}$.

Note that we know that the SCML occurs only when the growth of phytoplankton within the surface mixed layer is nutrient-limited; thus we further assume the surface nutrients value is negligible. Using the assumption of small $\mathrm{Chl} a$ at the top and the bottom boundaries of the model domain, we obtain

$h=\frac{K_{\mathrm{v} 2}}{w} N\left(z_{\mathrm{b}}\right)$,

and the intensity of SCML is

$P_{\max }=\frac{K_{\mathrm{v} 2}}{\sqrt{2 \pi} \sigma w} N\left(z_{\mathrm{b}}\right)$,

where $N\left(z_{\mathrm{b}}\right)$ is the nutrients concentration at depth $z_{\mathrm{b}}$. Therefore, with $\alpha=1$, the intensity of SCML is affected by the ambient nutrients concentration below the surface mixed layer. The total Chl $a$ in the water column depends on the sinking velocity of phytoplankton and the diffusivity, but it is independent of the growth rate and loss rate of phytoplankton. Analogous results have been obtained by Liccardo et al. (2013). Beckmann and Hense (2007) also found a similar result by introducing an explicit compartment for the detritus in their models. 
Acknowledgements. We gratefully acknowledge K. Fennel, E. Boss, J. Pitarch, and the two anonymous reviewers for constructive and insightful reviews. We also particularly thank X. H. Liu and Z. Y. Cai for programming assistance and valuable advice. This work is funded in part by the National Key Basic Research Program of China under contract 2014CB953700; the National Nature Science Foundation of China under contracts 41406010, 41210008, and 41106007; and the China Postdoctoral Science Foundation under contract 2013M541958.

Edited by: K. Fennel

\section{References}

Anderson, G. C.: Subsurface chlorophyll maximum in the northeast Pacific Ocean, Limnol. Oceanogr., 14, 386-391, 1969.

Ardyna, M., Babin, M., Gosselin, M., Devred, E., Bélanger, S., Matsuoka, A., and Tremblay, J. E.: Parameterization of vertical chlorophyll $a$ in the Arctic Ocean: impact of the subsurface chlorophyll maximum on regional, seasonal and annual primary production estimates, Biogeosciences, 10, 4383-4404, doi:10.5194/bg-10-4383-2013, 2013.

Ayata, S., Lévy, M., Aumont, O., Sciandra, A., Sainte-Marie, J., Tagliabue, A., and Bernard, O.: Phytoplankton growth formulation in marine ecosystem models: should we take into account photo-acclimation and variable stoichiometry in oligotrophic areas?, J. Marine Syst., 125, 29-40, 2013.

Beckmann, A. and Hense, I.: Beneath the surface: Characteristics of oceanic ecosystems under weak mixing conditions-A theoretical investigation, Prog. Oceanogr., 75, 771-796, 2007.

Behrenfeld, M. J. and Boss, E. S.: Resurrecting the ecological underpinnings of ocean plankton blooms, Annu. Rev. Mar. Sci., 6, 167-194, 2014.

Bienfang, P. K. and Harrison, P. J.: Sinking-rate response of natural assemblages of temperate and subtropical phytoplankton to nutrient depletion, Mar. Biol., 83, 293-300, 1984.

Bowdon, K. F.: Physical oceanography of coastal waters, Limnol. Oceanogr., 30, 449-450, 1985.

Cai Y. M., Ning X. R., and Liu C. G.: Synechococcus and Prochlorococcus growth and mortality rates in the northern China Sea: range of variations and correlation with environmental factors, Acta Ecol. Sin., 7, 2237-2246, 2006.

Camacho, A.: On the occurrence and ecological features of deep chlorophyll maxima (DCM) in Spanish stratified lakes, Limnetica, 25, 453-478, 2006.

Chen, C. C., Shiah, F. K., Chung, S. W., and Liu, K. K.: Winter phytoplankton blooms in the shallow mixed layer of the South China Sea enhanced by upwelling, J. Marine Syst., 59, 97-110, 2006.

Cianca, A., Helmke, P., Mouriño, B., Rueda, M. J., Llinás, O., and Neuer, S.: Decadal analysis of hydrography and in situ nutrient budgets in the western and eastern North Atlantic subtropical gyre, J. Geophys. Res., 112, C07025, 1-18, 2007.

Cianca, A., Godoy, J. M., Martin, J. M., Perez Marrero, J., Rueda, M. J., Llinás, O., and Neuer, S.: Interannual variability of chlorophyll and the influence of low frequency climate models in the North Atlantic subtropical gyre, Global Biogeochem. Cy., 26, doi:10.1029/2010GB004022, 2012.
Cloern, J. E., Grenz, C., and Vidergar-Lucas, L.: An empirical model of the phytoplankton chlorophyll: carbon ratio-the conservation factor between productivity and growth rate, Limnol. Oceanogr., 40, 1313-1321, 1995.

Cullen, J. J.: The deep chlorophyll maximum: comparing vertical profiles of chlorophyll $a$, Can. J. Fish. Aquat. Sci., 39, 791-803, 1982.

Cullen, J. J. and Eppley, R. W.: Chlorophyll maximum layers of the Southern California Bight and possible mechanisms of their formation and maintenance, Oceanol. Acta, 1, 23-32, 1981.

Dekshenieks, M. M., Donaghay, P. L., Sullivan, J. M., Rines, J. E., Osborn, T. R., and Twardowski, M. S.: Temporal and spatial occurrence of thin phytoplankton layers in relation to physical processes, Mar. Ecol-Prog. Ser., 223, 61-71, 2001.

Denman, K. L. and Gargett, A. E.: Time and space scales of vertical mixing and advection of phytoplankton in the upper ocean, Limnol. Oceanogr., 28, 801-815, 1983.

Fee, E. J.: The vertical and seasonal distribution of chlorophyll in lakes of the Experimental Lakes Area, northwestern Ontario: Implications for primary production estimates, Limnol. Oceanogr., 26, 767-783, 1976.

Fennel, K. and Boss, E.: Subsurface maxima of phytoplankton and chlorophyll: Steady-state solutions from a simple model, Limnol. Oceanogr., 48, 1521-1534, 2003.

Gabric, A. J. and Parslow, J.: Effect of physical factors on the vertical distribution of phytoplankton in eutrophic coastal waters, Aust. J. Mar. Fishwater Res., 40, 559-569, 1989.

Ghosal, S. and Mandre, S.: A simple model illustrating the role of turbulence on phytoplankton blooms, J. Math. Biol., 46, 333346, 2003.

Haney, J. D.: Modeling phytoplankton growth rates, J. Plankton Res., 18, 63-85, 1996.

Hanson, C. E., Pesant, S., Waite, A. M., and Pattiaratchi, C. B.: Assessing the magnitude and significance of deep chlorophyll maxima of the coastal eastern Indian Ocean, Deep-Sea Res. Pt. II, 54, 884-901, 2007.

Hense, I. and Beckmann, A.: Revisiting subsurface chlorophyll and phytoplankton distributions, Deep-Sea Res. Pt. I, 55, 1193-1199, 2008.

Hodges, B. A. and Rudnick, D. L.: Simple models of steady deep maxima in chlorophyll and biomass, Deep-Sea Res. Pt. I, 51, 999-1015, 2004.

Hood, R. R., Bates, N. R., Capone, D. G., and Olson, D. B.: Modeling the effect of nitrogen fixation on carbon and nitrogen fluxes at BATS, Deep-Sea Res. Pt. II, 48, 1609-1648, 2001.

Huisman, J. and Sommeijer, B.: Maximal sustainable sinking velocity of phytoplankton, Mar. Ecol-Prog. Ser., 244, 39-48, 2002.

Huisman, J., Thi, N., Karl, D. M., and Sommeijer, B.: Reduced mixing generates oscillations and chaos in the oceanic deep chlorophyll maximum, Nature, 439, 322-325, 2006.

Jamart, B. M., Winter, D. F., and Banse, K.: Sensitivity analysis of a mathematical model of phytoplankton growth and nutrient distribution in the Pacific Ocean off the northwestern US coast, J. Plankton Res., 1, 267-290, 1979.

Klausmeier, C. A. and Litchman, E.: Algal games: The vertical distribution of phytoplankton in poorly mixed water columns, Limnol. Oceanogr., 8, 1998-2007, 2001. 
Lee Chen, Y.: Spatial and seasonal variations of nitrate-based new production and primary production in the South China Sea, Deep-Sea Res. Pt. I, 52, 319-340, 2005.

Lewis, M. R., Cullen, J. J., and Platt, T.: Phytoplankton and thermal structure in the upper ocean: consequences of nonuniformity in chlorophyll profile, J. Geophys. Res., 88, 2565-2570, 1983.

Lewis, M. R., Harrison, W. G., Oakey, N. S., Hebert, D., and Platt, T.: Vertical nitrate fluxes in the oligotrophic ocean, Science, 234, 870-873, 1986.

Liccardo, A., Fierro, A., Iudicone, D., Bouruet-Aubertot, P., and Dubroca, L.: Response of the Deep Chlorophyll Maximum to fluctuations in vertical mixing intensity, Prog. Oceanogr., 2013, 33-46, 2013.

Liu, H., Chang, J., Tseng, C. M., Wen, L. S., and Liu, K. K.: Seasonal variability of picoplankton in the Northern South China Sea at the SEATS station, Deep-Sea Res. Pt. II, 54, 1602-1616, 2007.

Lu, Z., Gan, J., Dai, M., and Cheung, A.: The influence of coastal upwelling and a river plume on the subsurface chlorophyll maximum over the shelf of the northeastern South China Sea, J. Marine Syst., 82, 35-46, 2010.

Mara On, E. and Holligan, P. M.: Photosynthetic parameters of phytoplankton from $50^{\circ} \mathrm{N}$ to $50^{\circ} \mathrm{S}$ in the Atlantic Ocean, Mar. Ecol.-Prog. Ser., 176, 191-203, 1999.

Mellard, J. P., Yoshiyama, K., Litchman, E., and Klausmeier, C. A.: The vertical distribution of phytoplankton in stratified water columns, J. Theor. Biol., 269, 16-30, 2011.

Mignot, A., Claustre, H., D’Ortenzio, F., Xing, X., Poteau, A., and Ras, J.: From the shape of the vertical profile of in vivo fluorescence to Chlorophyll-a concentration, Biogeosciences, 8, 23912406, doi:10.5194/bg-8-2391-2011, 2011.

Mignot, A., Claustre, H., Uitz, J., Poteau, A., D’Ortenzio, F., and Xing, X.: Understanding the seasonal dynamics of phytoplankton biomass and the deep chlorophyll maximum in oligotrophic environments: A Bio-Argo float investigation, Global Biogeochem. Cy., 28, 2013G-4781G, 2014.

Morel, A.: Optical modeling of the upper ocean in relation to its biogenous matter content (case I waters), J. Geophys. Res., 93, 749-768, 1988.

Ono, S., Ennyu, A., Najjar, R. G., and Bates, N. R.: Shallow remineralization in the Sargasso Sea estimated from seasonal variations in oxygen, dissolved inorganic carbon and nitrate, DeepSea Res. Pt. II, 48, 1567-1582, 2001.

Oschlies, A.: Model-derived estimates of new production: New results point towards lower values, Deep-Sea Res. Pt. II, 48, $2173-$ 2197, 2001.

Pedrós-Alió, C., Calderón-Paz, J. I., Guixa-Boixereu, N., Estrada, M., and Gasol, J. M.: Bacterioplankton and phytoplankton biomass and production during summer stratification in the northwestern Mediterranean Sea, Deep-Sea Res. Pt. I, 46, 9851019, 1999.

Pérez, V., Fernández, E., Mara Ón, E., Morán, X., and Zubkov, M. V.: Vertical distribution of phytoplankton biomass, production and growth in the Atlantic subtropical gyres, Deep-Sea Res. Pt. I, 53, 1616-1634, 2006.

Pitarch, J., Odermatt, D., Kawka, M., and Wüest, A.: Retrieval of vertical particle concentration profiles by optical remote sensing: a model study, Opt. Express, 22, A947-A959, 2014.
Platt, T., Sathyendranath, S., Caverhill, C. M., and Lewis, M. R.: Ocean primary production and available light: further algorithms for remote sensing, Deep-Sea Res. Pt. I, 35, 855-879, 1988.

Prairie, J. C., Franks, P. J. S., Jaffe, J. S., Doubell, M. J., and Yamazaki, H.: Physical and biological controls of vertical gradients in phytoplankton, Limnol. Oceanogr., 1, 75-90, 2011.

Raven, J. A. and Richardson K.: Photosynthesis in marine environments. In: Topics in Photosynthesis, Elsevier, edited by: Baker, N. R. and Long, S., 7, 337-399, 1986.

Richardson, A. J., Silulwane, N. F., Mitchell-Innes, B. A., and Shillington, F. A.: A dynamic quantitative approach for predicting the shape of phytoplankton profiles in the ocean, Prog. Oceanogr., 59, 301-319, 2003.

Riley, G. A., Stommel, H., and Bumpus, D. F.: Quantitative ecology of the plankton of the western North Atlantic, Bulletin Bingham Oceanogra. Collect., 12, 1-69, 1949.

Ryabov, A. B., Rudolf, L., and Blasius, B.: Vertical distribution and composition of phytoplankton under the influence of an upper mixed layer, J. Theor. Biol., 263, 120-133, 2010.

Salihoglu, B., Garçon, V., Oschlies, A., and Lomas, M. W.: Influence of nutrient utilization and remineralization stoichiometry on phytoplankton species and carbon export: A modeling study at BATS, Deep-Sea Res. Pt. I, 55, 73-107, 2008.

Sharples, J., Moore, C. M., Rippeth, T. P., Holligan, P. M., Hydes, D. J., Fisher, N. R., and Simpson, J. H.: Phytoplankton distribution and survival in the thermocline, Limnol. Oceanogr., 46, 486-496, 2001.

Siswanto, E., Ishizaka, J., and Yokouchi, K.: Estimating chlorophyll-a vertical profiles from satellite data and the implication for primary production in the Kuroshio front of the East China Sea, J. Oceanogr., 61, 575-589, 2005.

Sullivan, J. M., Donaghay, P. L., and Rines, J. E.: Coastal thin layer dynamics: consequences to biology and optics, Cont. Shelf Res., 30, 50-65, 2010.

Sverdrup, H. U.: On conditions for the vernal blooming of phytoplankton, J. Cons. int. Explor. Mer., 18, 287-295, 1953.

Takahashi, M. and Hori, T.: Abundance of picophytoplankton in the subsurface chlorophyll maximum layer in subtropical and tropical waters, Mar. Biol., 79, 177-186, 1984.

Tjiputra, J. F., Polzin, D., and Winguth, A. M.: Assimilation of seasonal chlorophyll and nutrient data into an adjoint three dimensional ocean carbon cycle model: Sensitivity analysis and ecosystem parameter optimization, Global Biogeochem. Cy., 21, 1-13, 2007.

Uitz, J., Claustre, H., Morel, A., and Hooker, S. B.: Vertical distribution of phytoplankton communities in open ocean: An assessment based on surface chlorophyll, J. Geophys. Res, 111, 1-23, 2006.

Varela, R. A., Cruzado, A., and Tintoré, J.: A simulation analysis of various biological and physical factors influencing the deepchlorophyll maximum structure in oligotrophic areas, J. Marine Syst., 5, 143-157, 1994.

Weston, K., Fernand, L., Mills, D. K., Delahunty, R., and Brown, J.: Primary production in the deep chlorophyll maximum of the central North Sea, J. Plankton Res., 27, 909-922, 2005.

Williams, C., Sharples, J., Mahaffey, C., and Rippeth, T.: Wind driven nutrient pulses to the subsurface chlorophyll maximum in seasonally stratified shelf seas, Geophys. Res. Lett., 40, 54675472, 2013. 
Wu Y. P. and Gao K. S.: Photosynthetic response of surface water phytoplankton assemblages to different wavebands of UV radiation in the South China Sea, Acta Oceanol. Sin., 5, 146-151, 2011.
Yoshiyama, K., Mellard, J. P., Litchman, E., and Klausmeier, C. A.: Phytoplankton competition for nutrients and light in a stratified water column, Am. Nat., 174, 190-203, 2009. 